\title{
Oral Cancer- The Nigerian Perspective
}

\section{Mercy Okoh ${ }^{1 *}$ and Dickson Sopuru Okoh ${ }^{2}$}

${ }^{1}$ Department of Oral Surgery and Pathology, University of Benin, Benin City, Edo State, Nigeria

${ }^{2}$ Department of Oral Pathology and Oral Medicine, University of Calabar, Calabar, Cross River, Nigeria

\begin{abstract}
Study background: In our environment, oral cancer is one of the most common lethal diseases encountered in dental practice. It is frequently diagnosed in the late stages because most patients present late in the course of the disease. This may be attributed to their low socioeconomic status, illiteracy, and some traditional beliefs in alternative native therapies. Some authors have reported on oral cancers specifically in their individual geographic settings; however, there is a paucity of reviews on Oral cancers generally in our environment. This study aims to review the prevalence, awareness and clinicopathologic patterns of oral cancers across the different geographic zones in Nigeria.
\end{abstract}

Methods: Information was sourced from journals, electronic data base such as Medline, Pubmed, Elsevier ScienceDirect and personal research work.

Result: Several prevalence rates have been reported in different geopolitical locations in our environment. Orofacial carcinomas were reported mostly in the older age groups while the Orofacial sarcomas were found in the slightly younger age groups. Squamous cell carcinoma was the predominant histopathological type. There is a low level of awareness of these lesions among the low socio-economic groups which makes them present late in our health care facilities hence a poor prognosis.

Conclusion: There is a need for increased awareness, advocacy and preventive care and early detection.

Keywords: Oral cancer; Orofacial carcinoma; Orofacial sarcomas; Prevalence; Awareness; Nigeria.

\section{Introduction}

Nigeria is a developing country in Africa and has a population of over 140 million persons as reported by the National Population Commission from the 2006 census and a land area of 923,768.64 sq. kilometers [1,2]. There are six geopolitical zones in the country and all the states in the country have primary, secondary and tertiary health care institutions. The major occupations in Nigeria include agriculture, administrative jobs, manufacturing, white-collar professional jobs and various artisan jobs [1].

The burden of cancer in Nigeria is unknown, mainly because of lack of statistics or under reporting [3]. In a study of cancer registry literature updated from all over the world, only $1 \%$ of the literature emanated from Africa compare to 34\% and 42\% from Europe and Asia respectively [4]. In the World Health Organization bulletin, report No.804 of 1990, it was reported that over 50 percent of cancer victims live in poor nations which have less than 10 percent of the resources for cancer care and control [3]. Presently, there are 11 cancer registries in Nigeria, located in various tertiary hospitals and most of them are poorly funded. They all produce hospital-based data. There are no community based or population based database $[1,3]$.

Oral cancer is one of the ten most common cancers worldwide and the five years survival rate is still disappointingly low [5]. It is a major health problem especially in developing countries [5,6]. It is a serious cause of morbidity and mortality worldwide $[7,8]$. Oral cancer comprises about $85 \%$ of all head and neck cancers [9].

Orofacial cancers may be derived from: epithelial tissues (carcinomas), mesenchymal tissues (sarcomas) and haematolymphoid tissues (leukaemias/lymphomas/plasmacytomas) [10]. Mortality resulting from oral cancer is strongly correlated with the stage of diagnosis, as detection of early stage lesions is associated with significantly improved survival with lower morbidity [11,12]. In our environment, oral cancer is frequently diagnosed in the late stages because most patients present to the hospital late into the course of the disease $[13,14]$. Oral cancer awareness campaign and advocacy is necessary to increase the awareness of oral cancer scourge among the population on the need for regular dental visits, early recognition, and the dangers associated with late presentation of orofacial malignancy [15]. Therefore, this paper aims to review the prevalence, awareness and clinico-histopathological patterns of oral cancers in our own environment.

\section{Literature Review}

Information was sourced from journals, electronic data base such as Medline, Pubmed, Elsevier ScienceDirect, and Cochrane Library and personal research work. The search words were oral cancers, Orofacial carcinoma, orofacial sarcoma, orofacial haematolymphoid cancer.

\section{Epidemiology of oral cancer in Nigeria}

Oral cancers generally show a broad geographic variation between populations arising from the lifestyle and the varying predisposing factors. It is one of the major global threats to public health [16]. Oral cancers have been reported as the $6^{\text {th }}$ most common cancer worldwide $[17,18]$. Several prevalence rates of oral cancers have been reported by several authors in different geopolitical locations in Nigeria. Orofacial

*Corresponding author: Dickson Sopuru Okoh, Department of Oral Pathology and Oral Medicine, University of Calabar, Calabar, Cross River, Nigeria, Tel: (+234) 08058500355; E-mail: okodick@yahoo.com

Received September 13, 2017; Accepted September 24, 2017; Published September 26, 2017

Citation: Okoh M, Okoh DS (2017) Oral Cancer- The Nigerian Perspective. J Mol Biomark Diagn 8: 369. doi: 10.4172/2155-9929.1000369

Copyright: $\odot 2017$ Okoh M, et al. This is an open-access article distributed under the terms of the Creative Commons Attribution License, which permits unrestricted use, distribution, and reproduction in any medium, provided the original author and source are credited. 
carcinomas were reported mostly in the older age groups while the Orofacial sarcomas were mostly found in the slightly younger age groups [15,18-20]. North central Nigeria reported that oral cancers constitute $7.6 \%$ of head and neck cancers (HNC) from a 15-year study of which carcinomas, sarcomas and lymphomas were $81.5 \%, 16.7 \%$ and $1.8 \%$ of the cases respectively [21]. In North Eastern Nigeria, Akinmoladun et al. [9] in Gombe reported that cancer of the oral cavity constitutes $19.5 \%$ of all head and neck malignancies, while Otoh et al. [22] in Maiduguri, reported an average rate of 20 cases of oral cancer per annum. Oji and Chukwuneke [14] in South eastern Nigeria reported that oral cancers accounted for $2.7 \%$ of all cancer cases seen at the University of Nigeria Teaching Hospital (UNTH) Enugu over a sixyear period. In South-South Nigeria, Okoh et al. [18] stated a prevalence of $18.7 \%$ in the University of Benin Teaching Hospital (UBTH) over a 25-year retrospective study. Also, Bassey et al. [15] in Calabar reported a prevalence of $25.1 \%$. In Lagos, South-West Nigeria, a study by Arotiba et al. [20] on all patients who presented with cancer arising in the oral cavity and adjacent structures at the Lagos University Teaching Hospital (a tertiary referral centre) over a 15-year period (19781992) reported a prevalence rate of $9.67 \%$ of all cancer. Also in that same center, a prevalence rate of $18 \%$ of oral cancers from all orofacial biopsies from 1993 to 2003 was reported by Ajayi et al. [19]. Amusa et al. [23] in Ile Ife, South-West Nigeria reported that oral cancers accounted for $36.8 \%$ of head and neck malignancies (Table 1). These findings suggest regional variation in the prevalence rate of orofacial cancers in Nigerians. In recent years, there have been indications that the incidence and mortality rates of oral cancer have started to increase especially among younger men [24]. This is in agreement with reports from Nigeria $[25,26]$.

\section{Awareness of oral cancer}

In our environment, oral cancer is one of the most common lethal diseases that will be encountered in dental practice $[13,20,27]$. It is frequently diagnosed in late stages because most patients present to the hospital late into the course of the disease for treatment hence a poor prognosis. This may be attributed to their low socioeconomic status, illiteracy, and some traditional beliefs in alternative native therapies $[21,28,29]$. Sadly, most patients in our environment present at advanced stage of the disease [30-33]. Ignorance, poverty and lack of trained personnel- ENT surgeons, maxillofacial surgeons, general surgeons, and family physicians- to make proper diagnosis and referral, high cost of drugs when they are available all contribute to the dismal state of late presentation [1]. A study done on the knowledge and practices of oral cancers among graduating Dental students in South-South Nigeria, showed that only about $23 \%$ of the students had good knowledge of oral cancers [6]. Although the graduating dental students easily identified alcohol and tobacco as risk factors for oral cancers, awareness of other risk factors such as poor nutrition, Oral infection by Human Papilloma Virus and sunlight was on the average [6].

\begin{tabular}{|c|c|c|}
\hline Geopolitical Zones & Authors & Prevalence (\%) \\
\hline South East & Oji and Chukwuneke [14] & 2.7 \\
\hline \multirow{2}{*}{ South South } & Okoh et al. [18] & 18.7 \\
\cline { 2 - 3 } & Bassey et al. [15] & 25.1 \\
\hline \multirow{2}{*}{ South West } & Arotiba et al. [20] & 9.7 \\
\cline { 2 - 3 } & Amusa et al. [23] & 36.8 \\
\hline North Central & Ajayi et al. [46] & 18 \\
\hline North East & Otoh et al. [21] & 7.6 \\
\hline North West & Akinmoladun et al. [9] & 19.5 \\
\hline
\end{tabular}

Table 1: Prevalence of Oral Cancers in Nigeria.
The late presentation to the hospital for treatment, coupled with the observation that majority of patients did not have prescribed treatments could be attributed to the delay in diagnosis arising from the nonavailability of dentists who would perform basic routine oral cancer screening of patients seen in the hospital, poor access to hospitals and the primary recourse to traditional medicine $[21,28,29]$.

\section{Risk factors of oral cancer}

It is believed that the etiology of oral cancer is multifactorial and that the process is a multiple, stepwise one [34]. Most oral cancers can be prevented by avoiding risk factors, such as tobacco and alcohol use, excessive sun exposure, sexual behaviors leading to exposure to the Human Papilloma virus (HPV), [35] ingestion of smoked fish, infections especially by viruses, dietary deficiencies and industrial pollution [5]. In a report from Maiduguri [31] northern region of the country, tobacco smoking, tobacco chewing and chewing of kola nuts were associated with carcinoma of oral cavity. Kola nuts (Cola acuminate) has been reported to promote palatal mucosa keratinization in cigarette smokers and is considered a co-carcinogen $[1,36]$. The carcinogenic potential of kola nut has been linked with the fact that it contains up to $5 \%$ to $10 \%$ of tannins which previously has been listed among compounds with known and suspected carcinogenic potentials [36]. Another study from Jos [37], stated that carcinomas were associated with alcohol use and tobacco smoking $(\mathrm{p}<0.001)$, while Kaposi sarcoma was more associated with HIV-positive patients. A study conducted in South-west Nigeria, revealed that not consuming fruits and vegetables regularly was associated with an increased risk of developing oral cancer (OR 3.0 and 1.32) [29]. Also, it was found that the serum levels of antioxidant vitamins $\mathrm{A}, \mathrm{C}$ and $\mathrm{E}$ were significantly lower in oral cancer patient compared with those of normal patients $(\mathrm{p}=0.001$, $\mathrm{p}=0.013$ and $\mathrm{p}=0.015$ respectively) [37]. Oji and Chukwuneke [14] in Enugu, found that patients with oral cancer in their tertiary health centre gave no history of tobacco or alcohol misuse. They postulated that poverty, malnutrition, lack of education, poor oral hygiene and chronic malaria may be more important in the aetiology and severity of oral cancer in their series [14]. Lawoyin et al. [38] in Ibadan in their study, found a lack of association between oral cancer incidence and the known risk behaviours, and they suggested further investigations into other predisposing factors such as nutrients, genetic predisposition and the role of chronic infections, and that one or more of these might be more relevant in this environment. Similarly, Arotiba et al. [39] affirmed that the aetiology of oral cancers in Nigeria is not clear, hence suggested a need for more investigations into the possible aetiological factors in our environment in order to offer a preventive approach to the management of the disease.

Today, we know that approximately $35 \%$ of oral cancers are positive for HPV-DNA [40] with $90 \%$ to $95 \%$ of these positive for HPV-16 [30]. The burden of HPV-related Head and Neck Cancers has been on the rise in the USA and other developed countries but this trend has not been reported in Nigeria or even in Africa [41]. There is paucity of studies of HPV associated oral cancers in Nigeria. Oga et al. [41] in their extensive study from the Pathology Departments of 4 tertiary health institutions in Nigeria- University of Benin Teaching Hospital (UBTH) and University of Calabar Teaching Hospital (UCTH) in Southern Nigeria, University of Abuja Teaching Hospital (UATH) and University of Ilorin Teaching Hospital (UITH) in Northern Nigeria on the role of HPV, were unable to detect HPV in all of the HNC samples in their series. Their result may suggest a low prevalence of HPV-related HNC among the adult population in Nigeria. Therefore, further studies should be done to attest the importance of HPV in the aetiopathogenesis of Oral Cancers in Nigeria. 


\section{Age distribution of oral cancer}

Cancers are known to occur more often with increasing age [42]. The increased incidence of cancers with advancing age may be partly due to the increasing level of free radical reactions with age. Also, there is said to be a diminishing ability of the immune system to eliminate altered cells, and so the effectiveness of cancer surveillance by immune cells is reduced with advancing age [5,43]. In Nigeria, a recent study from Lagos showed that the peak age of incidence of oral cancer was in the $5^{\text {th }}$ decade of life [20]. A review of squamous cell carcinoma (SCC) of the oral cavity in Lagos found the peak incidence in the $3^{\text {rd }}$ and $5^{\text {th }}$ decade of life, with $40 \%$ of cases occurring in patients under age of 40 years [44]. The mean age of occurrence of salivary gland malignancies in Enugu and in Lagos was 40 years [45,46]. However, some studies have reported oral cancer cases occurring in persons older than 40 years. Okoh et al. [18] reported a mean age of oral carcinomas in Benin as 51 \pm 17.9 years, with the highest occurrence within the seventh decade of life with Squamous Cell Carcinoma occurring mostly in the sixth and seventh decades of life. A study in Calabar [15] Nigeria reported a peak incidence of squamous cell carcinoma in the sixth and seventh decades while Burkitt's lymphoma and rhabdomyosarcoma were observed around the first decade. Orofacial carcinomas were reported mostly in the older age groups while the Orofacial sarcomas and lymphomas were mostly found in the slightly younger age groups $[15,19]$. Ajayi et al. in Lagos [19] reported 75\% of oral carcinomas occurring above 40 years of age. Patients with carcinoma were older than those with sarcomas and lymphomas $(\mathrm{P}<0.01)$, while those with lymphomas were significantly younger than those with sarcomas $(\mathrm{P}<0.01)[19]$.

\section{Sex distribution of oral cancer}

Oral cancer affects males more frequently than females, although the ratio is equalizing [47]. Also, most studies from Nigeria have shown oral cancer to be more prevalent in males than females $[19,20,48,49]$. However, Otoh et al. [22] in Maiduguri North-east Nigeria found a male to female ratio of 3:4 and suggested that the relative higher preponderance of females in their study may be attributed to the increasing exposure of females in North-eastern Nigeria to carcinogens such as tobacco and alcohol. Other studies also reported female predilection for oral carcinomas $[14,19]$.

\section{Site distribution of oral cancer}

The tongue and floor of the mouth have been cited as the two most common sites for oral cancer in developed countries [9,50]. In Southsouth Nigeria, a study in University of Benin Teaching Hospital, [18] reported palate as the most common site for orofacial carcinomas. Similarly, Otoh et al. [22] also reported the palate as the most common site of intraoral carcinomas in northern Nigerians. Some Nigerian studies from Ibadan, however, show that the tongue, palate and the mandibular alveolus are the sites most commonly affected with the floor of mouth and buccal mucosa being the least affected [20,51]. However, some other contrasting studies have stated mandibular gingiva as the most common site of occurrence followed by the maxillary gingiva and the tongue [44]. The maxillary antrum is observed as the most common site in other studiesin Lagos [19,52]. Figures 1 and 2 shows a clinical photograph of Squamous cell carcinoma (SCC) of the tongue and Mucoepidermoid Carcinoma of the palate respectively while Figure 3 is that of a young male with Burkitt's lymphoma affecting the jaws.

\section{Histopathological types of the oral cancers}

Some studies in Nigeria have reported on the broad and specific histopathological types of orofacial malignancies $[9,15,18,19,22,27,31]$.

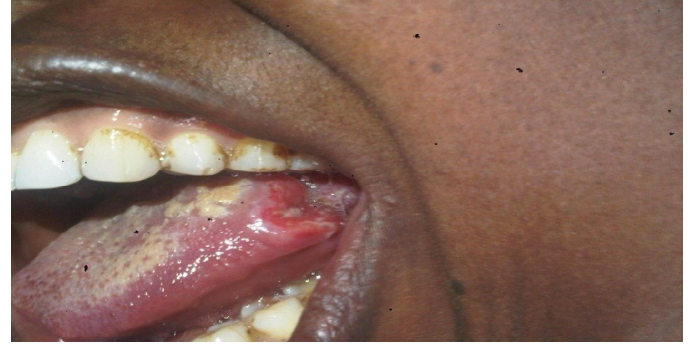

Figure 1: Squamous cell carcinoma of the tongue showing a large ulcer on the lateral border of the tongue.

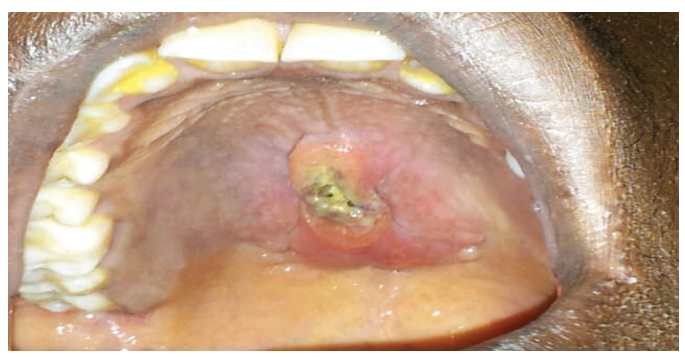

Figure 2: Mucoepidermoid carcinoma of the palate presenting as an ulcerated swelling on the midline of the palate.

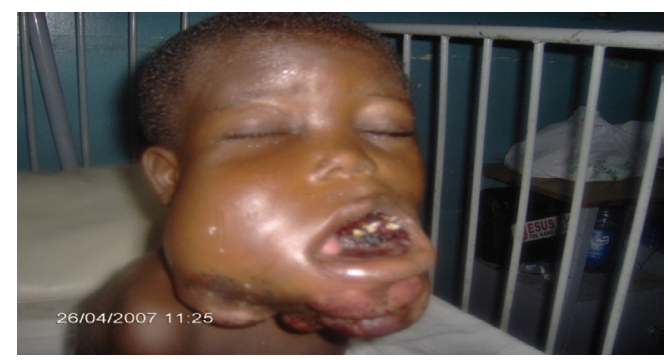

Figure 3: Burkitt's lymphoma. Firm masses involving the upper and the lower jaws.

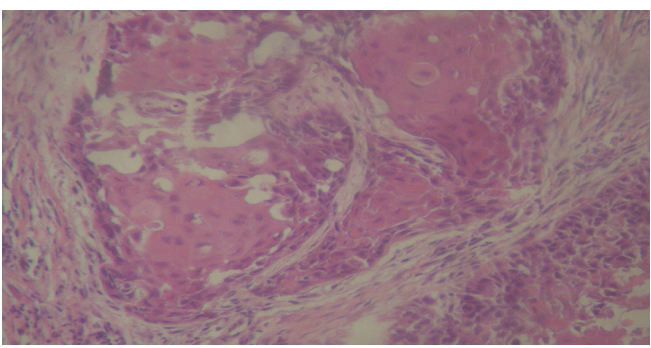

Figure 4: Histopathologic section of a squamous cell carcinoma showing islands of dysplastic squamous cells with keratin pearls surrounded by fibrous stroma ( $\mathrm{H}$ and $\mathrm{E} \times 400)$

Orofacial cancers may be derived from: epithelial tissues (carcinomas), mesenchymal tissues (sarcomas) and haematolymphoid tissues (leukaemias/lymphomas/plasmacytomas) [10]. Orofacial carcinoma is reported as the most common malignancy known to affect the oral and maxillofacial region in our environment. Arotiba et al. [52] and Ajayi et al. [19] in Lagos, South-west, Nigeria have reported a prevalence of $68.2 \%$ and $69 \%$ respectively for carcinomas among the oral cancers. Arotiba et al. [52] 2006 found the carcinomas as consisting mostly of SCC $(42.9 \%)$ and salivary gland carcinomas (25.4\%). They observed 
that the sarcomas (12.4\%) were mostly the Rhabdomyosarcoma followed by Chondrosarcoma while the lymphomas (14.3\%) were mostly the Burkitt's lymphoma. Similarly, Ajayi et al. [19] in their review reported that the carcinomas were also mostly SCC constituting $44 \%$ of all the malignancies. In their finding, the sarcomas (18\%) were the second most common cancer followed by the lymphomas (13\%). Osteosarcoma and Burkitt's lymphoma were the predominant sarcoma and lymphoma respectively [19].

Also, Adeyemi et al. [53] reported a prevalence of $71.1 \%$ for carcinomas among head and neck cancers analyzed in Ibadan (SouthWest, Nigeria). The two most common head and neck cancers in their series were SCC, which accounted for $47.8 \%$ of cases, followed by lymphomas which accounted for 19.3\% [53]. Adisa et al. [27] reported that the epithelial malignancies (carcinomas) constitute $73.4 \%$ of all the cases while Lymphomas and sarcomas were $17.5 \%$ and $8.9 \%$ of cases respectively.

Otoh et al. [31,37] reported a prevalence of $68.4 \%$ and $60.8 \%$ for carcinomas among head and neck cancers analyzed in Maiduguri and Jos respectively in both cities in Northern Nigeria. Also in the same geopolitical region, Akinmoladun et al. [9] found in their series epithelial malignancies to account for $56.9 \%$ of cases while lymphomas and sarcomas constitute $21.5 \%$ and $10.3 \%$ respectively.

In Benin, South-South Nigeria, Okoh et al. [18] found that orofacial cancers account for $18.7 \%$ of all biopsied specimens which consist of carcinomas (56.1\%), lymphomas (25.6\%) and sarcomas (18.2\%). They also reported SCC as the most common orofacial carcinoma. The salivary gland adenocarcinoma was the second most common histopathological type of carcinoma found in their series [18]. Figure 4 is a photomicrograph of a squamous cell carcinoma.

\section{Discussion}

\section{Oral cancer in view of the future in Nigeria}

Oral cancer awareness campaign and advocacy is necessary to steer the awareness of the populace on the need for regular dental visits, early recognition, and the dangers associated with late presentation of orofacial malignancy [15]. Today, we know that approximately $35 \%$ of oral cancers are positive for HPV-DNA [40], with $90 \%$ to 95\% of these positive for HPV-16. Investigators should use this more recent knowledge to inform future studies; and it should be requisite in screening and detection of oral cancers in Nigeria. The studies on oral cancers in Nigeria are hospital-based. To determine the national incidence of oral cancers in Nigeria, population-based studies should be undertaken [1]. Longitudinal and cohort studies are also needed to identify possible risk factors for the development of cancer of the head and neck region in our population. The investigation of the molecular events associated with oral cancer in Nigeria is desirable, since it has previously been shown that there are racial differences in molecular events that lead to oral cancer [5]. The molecular changes found to be associated with oral carcinomas in western countries (UK, USA and Australia) are mainly p53 mutations but these are rare in the east (India and South-East Asia) where more of RAS oncogenes abnormalities are common [54].

\section{Conclusion}

Carcinomas were reported as the most common oral cancer in Nigeria mostly in the older age groups above 40 years. Squamous cell carcinoma is the predominant histopathological type seen. There is a low level of awareness of these lesions especially among the low socio-economic group which makes them present late in our health care facilities for treatment hence a poor prognosis. There is a need for increased awareness, advocacy, preventive care and oral cancer screening for early detection.

\section{References}

1. Lilly-Tariah da OB, Somefun AO, Adeyemo WL (2009) Current evidence on the burden of head and neck cancers in Nigeria. Head Neck Oncol 1: 14.

2. Nigeria year book (1981), Times press Ltd. Apapa, Nigeria. pp. 451-467.

3. Popoola AO, Omodele FO, Oludara MA, Ibrahim NA, Igwilo Al, et al. (2013) Prevalence and pattern of cancers among adults attending a tertiary health institution in Lagos. IOSR-JDMS 6: 68-73.

4. Howlader N, Noone AM, Krapcho M, Neyman N, Aminou R, et al. (2011) SEER Cancer Statistics Review 1975-2008.

5. Lawal AO, Kolude B, Adeyemi BF (2013) Oral cancer: The Nigerian experience. Int J Med Med Sci 5: 178-183.

6. Okoh M, Enabulele J (2015) Knowledge and practices regarding oral cancer among graduating dental students. Indian J Oral Sci 6: 14-18.

7. Uti OG, Fashina AA (2006) Oral cancer education in dental schools: Knowledge and experience of Nigerian undergraduate students. J Dent Education 70: $676-80$

8. Binnie WH, Rankin KV (1988) Epidemiology of oral cancer, oral cancer: Clinical and pathological considerations. CRC Press Inc. Boca Raton FL, USA.

9. Akinmoladun VI, Akintububo OB, Adisa AO, Ojo EO, Ayuba D (2013) Evaluation of the histopathology of orofacial lesions in a North-East Nigerian tertiary centre. Ann Afr Med 12: 105-109.

10. Slootweg PJ, Eveson JW (2005) Tumours of the oral cavity and oropharynx WHO Classification of Tumours. Pathology and genetics of head and neck tumours. Lyon: IARC press, France.

11. Kurokawa H, Zhang M, Matsumoto S, Yamashita $\mathrm{Y}$, Tomoyose T, et al. (2005) The high prognostic value of the histologic grade at the deep invasive front of the tongue squamous cell carcinoma. J Oral Pathol Med 34: 329-333.

12. Silveria EJ, Godoy GP, Lins RD, ArrudaMde L, Ramos CC, et al. (2007) Correlation of clinical, histological and cytokeratin profiles of squamous cell carcinoma of the oral tongue with prognosis. Int J Surg Pathol 15: 376-383.

13. Gbotolorun O, Emeka C, Effiom O, Adewole R, Ayodele A (2016) An audit of malignant oro-facial tumors presenting at a tertiary hospital in Lagos. Annals Medical Health Sci Res 6: 133-136.

14. Oji C, Chukwuneke F (2007) Oral cancer in Enugu, Nigeria, 1998-2003. Br J Oral Maxillofac Surg 45: 298-301.

15. Bassey GO, Osunde OD, Anyanechi CE (2015) Analysis of 46 cases of malignant jaw tumours in Calabar, Nigeria. Niger Med J 56: 240-243.

16. Tanaka T, Ishigamori $R$ (2011) Understanding carcinogenesis for fighting oral cancer. J Oncol 2011: 603740.

17. Tadbi AA, Mehrabani D, Heydari ST (2009) Sociodemographic and etiologic differences of malignant orofacial tumors in Iran. J Craniofac Surg 20: 837-840.

18. Okoh DS, Orikpete EV, Omoregie OF, Ojo MA (2015) A Study of the clinicopathologic patterns of orofacial carcinomas in a Nigerian population. Afr $\mathrm{J}$ Oral and Maxillofac Path Med 1: 10-17.

19. Ajayi OF, Adeyemo WL, Ladeinde AL, Ogunlewe MO, Effiom OA, et al. (2007) Primary malignant neoplasms of orofacial origin: A retrospective review of 256 cases in a Nigerian teaching hospital. Int J Oral Maxillofac Surg 36: 403-408.

20. Arotiba JT, Obiechina AE, Fasola OA, Ajagbe HA (1999) Oral squamous cell carcinoma: A review of 246 Nigerian cases. Afr J Med Med Sci 28: 141-144.

21. EC Otoh, NW Johnson, BM Mandong, IS Danfillo (2004) Pattern of oral cancers in the North Central zone of Nigeria. Afr J Oral health 1: 47-53.

22. Otoh EC, Johnson NW, Olasoji HO, Danfillo IS, Adeleke OA (2005) Intra-ora carcinoma in Maiduguri, North-Eastern Nigeria. Oral Dis 11: 379-385.

23. Amusa YB, Olabanji JK, Akinpelu VO, Olateju SO, Agbakwuru EA (2004) Pattern of head and neck malignant tumors in a Nigerian teaching hospital: A 10-year review. West Afr J Med 23: 280-285. 
24. Hindle I, Downer M, Speight $P$ (1994) Necessity for preventive strategies in oral cancer. Lancet 343: 178-179.

25. Bhatia PL (1990) Head and neck cancer in Plateau State of Nigeria. West Afr J Med 9: 304-310.

26. Nwawolo CC, Ajekigbe AT, Oyeneyin JO, Nwankwo KC, Okeowo PA (2001) Pattern of head and neck cancers among Nigerians in Lagos. West Afr J Med 20: 111-116.

27. Adisa AO, Adeyemi BF, Oluwasola AO, Kolude B, Akang EE, et al. (2011) Clinico-pathological profile of head and neck malignancies at University College Hospital, Ibadan, Nigeria. Head Face Medicine 7: 9.

28. Solanke TF (2000) Cancer in the Nigerian setting (with particular reference to Ibadan). Arch Ibadan Med 1: 3-5.

29. Lawal A, Kolude B, Adeyemi BF, Lawoyin J, Akang E (2011) Social profile and habits of oral cancer patients in Ibadan. Afr J Med Med Sci 40: 247-251.

30. D'Souza G, Kreimer AR, Viscidi R (2007) Case-control study of human papilloma virus and oropharyngeal cancer. N Engl J Med 356:1944-1956.

31. Otoh EC, Johnson NW, Danfillo IS (2004) Primary head and neck cancers in North Eastern Nigeria. West Afr J Med. 2004; 23:305-313.

32. Sowemimo GOA, Ademiluyi SA, Oyeneyin JO (1978) Salivary gland tumours. Nig Med J 8: 119-123.

33. Gbotolorun OM, Bakare T, Olojede AC, Adeniyi A, Emeka Cl, et al. (2014) A survey of patients with oro-facial tumours in two tertiary hospitals in Lagos, Nigeria. Niger Med Pract 66: 3-5.

34. Wood NK, Sawyer DR (2009) Oral cancer, differential diagnosis of oral and maxillofacial lesions. Mosby: Elsevier publisher, USA.

35. Tachezy R, Klozar J, Salakova M (2005) HPV and other risk factors of oral cavity/oropharyngeal cancer in the Czech Republic. Oral Dis 11: 181-185.

36. Odukoya O, Roberts T, Arole G (1990) A cytologic study of the effect of kolanut on the keratinization of the palatal mucosa of Nigerian smokers. Afr Dent $\mathrm{J} 4$ : 1-5.

37. Otoh EC, Johnson NW, Mandong BM, Danfillo IS (2006) Primary head and neck cancers in Jos, Nigeria: a re-visit.West Afr J Med 25: 92-100.

38. Lawoyin JO, Aderinokun GA, Kolude B, Adekoya SM, Ogundipe BF (2003) Oral cancer awareness and prevalence of risk behaviours among dental patients in South-Western Nigeria. Afr J Med Med Sci 32: 203-207.

39. Arotiba JT, Olusanya AA, Lawal AO, Akinmoladun VI (2010) Trends of oral cancer in University College Hospital, Ibadan, Nigeria. NDJ 18: 24-27.

40. Kreimer AR, Clifford GM, Boyle P, Franceschi S (2005) Human papilloma virus types in head and neck squamous cell carcinomas worldwide: A systematic review. Cancer Epidemiol Biomarkers Prev 14: 467-475.

41. Oga EA, Schumaker LM, Alabi BS, Obaseki D, Umana A, et al. (2016) Paucity of HPV-related head and neck cancers (HNC) in Nigeria. PLoS ONE 11: e0152828.

42. Vokes EE, Weichselbaum RR, Lippman SM, Hong WK (1993) Head and neck cancer. New Engl J Med 328: 184-194.

43. Enwonwu CO, Meeks VI (1995) Bionutrition and oral cancer in humans. Critical Rev Oral Biol Med 6: 5-17.

44. Effiom OA, Adeyemo WL, Omitola OG, Ajayi OF, Emmanuel MM, et al. (2008) Oral squamous cell carcinoma: A clinicopathologic review of 233 cases in Lagos, Nigeria. J Oral Maxillofac Surg 66: 1595-1599.

45. Ezeanolue BC (1999) Salivary gland neoplasm: A descriptive analysis of the pattern seen in Enugu. West Afr J Med 18: 179-182.

46. Ladeinde AL, Adeyemo WL, Ogunlewe MO, Ajayi OF, Omitola OG (2007) Salivary gland tumours: A 15-year review at the Dental centre Lagos University Teaching Hospital. Afr J Med Med Sci 36: 299-304.

47. Scully C (2013) Rule for cancer diagnosis. Br Dent J 215: 265-266.

48. Odukoya O, Mosadomi A, Sawyer DR, Orejobi A, Kekere-Ekun A (1986) Squamous cell carcinoma of the oral cavity- A clinicopathological study of 106 Nigerian cases. J Maxillofac Surg 14: 267- 269.

49. Applebaun E, Ruhlen TN, Kronenberg FR (2009) Oral cancer knowledge, attitudes and practices. a survey of dentists and family physiciansin Massachusetts. J Am Dent Assoc 140: 461-467.

50. Collela G, Gaeta GM, Moscarello A (2008) Oral cancer and dentists: Knowledge, attitudes and practices in Italy. Oral Oncol 44: 393-399.

51. Daramola JO, Ajagbe HA, Oluwasanmi JO (1979) Pattern of oral cancer in a Nigerian population. Br J Oral Surg 17: 123-128.

52. Arotiba GT, Ladeinde AL, Oyeneyin JO, Nwawolo CC, Banjo AA, et al. (2006) Malignant orofacial neoplasms in Lagos, Nigeria. East Afr Med J 83: 62-68.

53. Adeyemi BF, Adekunle LV, Kolude BM, Akang EE, Lawoyin JO (2008) Head and neck cancer- A clinicopathological study in a tertiary care centre. J Natl Med Assoc 100: 690-697.

54. Scully C, Bedi R (2000) Ethnicity and oral cancer. Lancet Oncol 1: 37- 42. 